\title{
Prototype for Internet support of pregnant women and mothers with type I diabetes: focus group testing
}

This article was published in the following Dove Press journal:

Psychology Research and Behavior Management

31 July 2012

Number of times this article has been viewed

\section{Annsofie Adolfsson 1,2 \\ Malin Jansson ${ }^{1,2}$}

'School of Life Sciences, University of Skovde, Skovde, Sweden; ${ }^{2}$ Department of Obstetrics and Gynaecology,

Skaraborg Hospital, Skovde, Sweden
Correspondence: Annsofie Adolfsson School of Life Sciences, University of Skövde, PO Box 408, SE 54I 28 Skövde, Sweden

Tel +46500448473

Fax +46500448499

Email annsofie.adolfsson@his.se
Background: The aim of this study was to pilot test a prototype website called MODIAB-web designed to support pregnant women and mothers with type 1 diabetes.

Method: A focus group was undertaken and the results were analyzed using qualitative content analysis.

Results: Eight subthemes were identified, comprising "blood glucose versus insulin," "application for smart phones," "the time aspect," "interface and technology," "forum," "direct link to the diabetes midwife," "ask the expert," and "lack of contact information." These subthemes were condensed into two main themes. The first theme was "easily understood interface, but in need of a more blood-glucose focused orientation" and the second theme was "forum for interaction with both equals and experts."

Conclusion: The women in this study had positive impressions of several of the MODIAB-web functions, including a forum for pregnant mothers with type 1 diabetes and the possibility of being able to put their blood glucose levels into a diagram which could be sent directly to the diabetes midwife. Access to articles and information via the "fact" tab and the ability to ask questions of experts were also significantly helpful to women in the focus group. Pregnant women and mothers with type 1 diabetes can gain support from such a Web-based self-help system.

Keywords: type 1 diabetes, web support, pregnancy, focus group interview

\section{Background}

Type 1 diabetes is estimated to occur in $0.5 \%$ of all pregnant women. ${ }^{1}$ Women with the disease have an increased risk of congenital malformation in their offspring, ${ }^{2}$ an increased risk of miscarriage, and an increased risk of prenatal mortality. ${ }^{3}$ Women with diabetes are also at risk of pre-eclampsia and have a high rate of cesarean delivery. ${ }^{4}$ Women at high risk of the aforementioned complications often experience negative feelings and insecurity related to childbirth. ${ }^{5}$

Pregnant women with pregestational diabetes have a sense of loss of control and may feel that diabetes has overshadowed their pregnancy, ${ }^{6}$ such that their attention is more focused on their diabetes and testing of blood glucose levels and adhering to a strict diet than on their pregnancy. They also feel anxious about the frequent testing, which causes them to worry constantly, feel extra pressure, and blame themselves for their condition. ${ }^{7}$ Women with type 1 diabetes also have an increased risk of excessive fetal growth and are often concerned that this will make labor difficult. Maternal and neonatal complications for women with type 1 diabetes following birth ${ }^{8}$ contribute to greater anxiety in pregnant women with pre-existing diabetes compared with nondiabetic pregnant women. ${ }^{9}$ 
The health care of women with type 1 diabetes seems to lack focus on the mother. The care of these women takes place in a number of different facilities because they must see a number of health care professionals at different locations. ${ }^{8}$ However, when a pregnant woman with diabetes takes control of her life by paying attention to her diet, physical activity, and health care, she gains a sense of control over her life in terms of meaningfulness and reconciliation of her issues with the disease. ${ }^{10}$ Pregnant women with type 1 diabetes often need to share their experiences with other pregnant women who also have diabetes to minimize feelings of isolation during pregnancy. ${ }^{8}$

Type 1 diabetic pregnant women and mothers of infants up to 6 months of age are cared for by a number of health care professionals, including a midwife in the maternal health unit, a diabetes midwife, and obstetricians in the antenatal unit. There is also the diabetic nurse at the health center and frequently there are other various professionals contributing to the care of these women, depending on the potential complications. How the care is organized and administered varies from region to region in Sweden. Contact with the health care system is normally on a weekly basis and this becomes more frequent as the pregnancy proceeds. It is not unusual for women in their third trimester to be in contact with the maternal health unit and/or antenatal unit as frequently as alternate days. ${ }^{11}$

Many pregnant women use the Internet when searching for pregnancy-related information, social networking, and support. Women report sometimes feeling dissatisfied with the information that they are given by their health care professionals and lack of access to professionals who can answer their questions, so they turn to the Internet as a source of information. ${ }^{12}$ Most pregnant women who seek pregnancy-related information on the Internet consider it to be reliable, but $70 \%$ of such women do not check the information they glean from the Internet with their midwife. Eventually, half of them verify the information that they receive from the Internet with their midwife later in pregnancy. ${ }^{13} \mathrm{~A}$ Web-based support system that focuses on pregnant women and mothers with type 1 diabetes currently does not exist. However, it has been found that patients can benefit from and be empowered by participating in online patient support groups. ${ }^{14}$

The MODIAB-web is a Swedish project developing and testing a Web-based support tool for type 1 diabetic pregnant women and mothers. Phase I has already been implemented, and this survey is part of a Phase II study designing relevant and necessary parts of a Web environment adapted for pregnant women and mothers with type 1 diabetes. The aim of this study was to analyze the experiences of pregnant women and mothers with type 1 diabetes using a prototype of the MODIAB-web by reporting on the communication between the women, their midwives, and the researchers and data programmers as part of this pilot program.

\section{Materials and methods}

Qualitative methods were chosen in order to satisfy the objectives of this study. The design consisted of an interactive focus group including women with type 1 diabetes who had also experienced pregnancy, breastfeeding, and nurturing of children. The prototype Website, MODIAB-web, consists of four sections. On the opening page, women with type 1 diabetes register a number of factors related to their disease, including blood glucose levels and insulin dosing information, such as number, time, and type. Food intake, physical activity, and psychological status are also recorded. This information was recorded as input data in the form of charts, tables, and diagrams to enable it to be available to the women so that they could manage their blood glucose levels on a daily basis, and also on a longer-term basis. The second section is informational and contains pertinent information that a woman with type 1 diabetes might need to be able to manage their disease in connection with their pregnancy, childbearing, and new motherhood. The third section in the prototype Website consists of a forum for social discussion with other women who are in the same situation. The fourth section is the database, which contains answers from experts to typical questions posed by women who are pregnant and have type 1 diabetes. The prototype was constructed from earlier studies ${ }^{5,7,8,10}$ and findings about the needs of women with type 1 diabetes.

\section{Data collection}

This study evolved from material gathered from interviews with participants in a focus group. ${ }^{15}$ The method was modified so that the prototype Website could be tested at the same time. The participants were sequestered in a room and given access to their own computer provided by the software company which designed the program for the MODIAB-web. The software company had two programmers present during the testing, as well as the main investigators in this study (AA and MJ). The principal author (AA) was also a participating researcher in the MODIAB-web project. The interviews were tape-recorded and at the same time the student author kept a log of the discussion that was taking place both during testing and in the discussion afterwards. 
The women were required to test the software and, if they had any questions during testing, they were directed to and answered by the software programmers or the supervisor. The student author did not participate in the interview and was only in charge of the protocol.

Immediately after testing, the study participants had a group discussion in which the programmers and the supervisor also participated. There were no questions determined in advance by either the investigators or the supervisor. After the discussion, one of the programmers asked the participants what they thought of the program. The discussion was based on what the women thought of the software and what impressions they developed during and after testing. The programmers were active participants in this conversation because they were in charge of the program and this was also an opportunity for them to get direct feedback from women using the program. The supervisor also had an active role in the conversation in answering the questions posed by the women. Thereafter, the recorded interview was transcribed verbatim into text by the student author.

\section{Participants}

This study was conducted at a college located in the middle of Sweden. It was undertaken in collaboration with diabetes midwives at an antenatal unit in a midsized hospital where women with diabetes were asked if they were interested in participating in a project to test a Website intended as a support tool for pregnant women and mothers with type 1 diabetes. Potential participants were invited during a 3 -month period in the summer of 2011. Of the five women who received the information letter and showed interest, three elected to participate in the interview. The other two women notified the study supervisor by email that they were unable to participate because of illness on the day the interview took place. The women were aged $30-40$ years. One woman lived in the countryside, one lived in a small town, and one lived in a midsized town. Their education level varied from completing secondary school to having gone to college (Table 1).

\section{Data analysis}

A latent qualitative content analysis was used for this study. The transcribed text was read as a whole to get an overall understanding of the content and was reread during the analysis process to keep continuity of focus. The text was read in sequence to identify contextual units, ${ }^{16}$ which were highlighted and identified with a marker. The units were further condensed and each unit was given a code. ${ }^{17}$ Krippendorff ${ }^{16}$ writes that "each unit must be coded and described in analyzable forms." In order to do that and to make the results comprehensible, a chart was made from the codes. The structure of the chart was taken from Graneheim and Lundman, ${ }^{18}$ who refer to Baxter ${ }^{19}$ and use definition themes to condense further the codes lifted from the text. Instead of "contextual unit" they use "condensed meaning unit." Because the Graneheim and Lundman ${ }^{18}$ chart is used to make the workflow and analysis understandable, the term "condensed meaning unit" was chosen for use. Figure 1 shows the steps taken in the process of condensing the transcribed text into themes. The themes reveal the latent essence of what the women from the focus group expressed in the interview.

\section{Ethical considerations}

Ethical approval and permission to carry out this study was granted by the regional ethics committee. Authorization was obtained from each woman to conduct and record the interview, and they were informed that all information would be treated confidentially and that they could terminate their participation at any time without any questions.

\section{Results}

Two themes were revealed by the process of condensation. The first theme was easily understood, ie, "easily understood interface, but needs more blood glucose-focused orientation." This theme reflects the women's understanding that they could start using the site at once without any training. However, at the same time, they felt that the focus was slightly misleading. The second theme was "a forum for interaction with both equals and experts." The women

Table I Background data for women in the focus group

\begin{tabular}{|c|c|c|c|c|c|c|c|c|c|c|}
\hline Number & $\begin{array}{l}\text { Age } \\
\text { (years) }\end{array}$ & $\begin{array}{l}\text { Highest } \\
\text { education }\end{array}$ & $\begin{array}{l}\text { Living } \\
\text { area }\end{array}$ & $\begin{array}{l}\text { Age at diabetes } \\
\text { onset (years) }\end{array}$ & $\begin{array}{l}\text { Insulin } \\
\text { method }\end{array}$ & Gravida & $\begin{array}{l}\text { Miscarriage } \\
\text { (n) }\end{array}$ & $\begin{array}{l}\text { Children } \\
\text { (n) }\end{array}$ & $\begin{array}{l}\text { Computer } \\
\text { literacy }\end{array}$ & Smartphone \\
\hline I & 30 & $\begin{array}{l}\text { Secondary } \\
\text { school }\end{array}$ & $\begin{array}{l}\text { Midsized } \\
\text { town }\end{array}$ & II & Pen & I & 0 & 0 & Yes & Yes \\
\hline 2 & 38 & College & Small town & 18 & Pen & 3 & I & I & Yes & No \\
\hline 3 & 38 & College & Countryside & 8 & Pen & 10 & 7 & 2 & Yes & No \\
\hline
\end{tabular}




\begin{tabular}{|c|c|c|c|c|}
\hline Meaning unit & Condensed meaning unit & Code & Subtheme & Theme \\
\hline $\begin{array}{l}\text { "... sure those who work with diabetes and pregnancy } \\
\text { know the facts about how diabetes works, but they can } \\
\text { never understand the feelings that are involved or how you } \\
\text { make it work in your everyday life. They can only provide } \\
\text { tips about how others deal with it. It is easier to talk with } \\
\text { someone who is actually in the exact same situation ..." }\end{array}$ & $\begin{array}{l}\text { Valuable with forum, to } \\
\text { get in contact with others } \\
\text { in the same situation }\end{array}$ & $\begin{array}{l}\text { Forum for } \\
\text { contact } \\
\text { with others }\end{array}$ & Forum & $\begin{array}{l}\text { Forum for } \\
\text { interaction } \\
\text { with both } \\
\text { equals and } \\
\text { experts }\end{array}$ \\
\hline $\begin{array}{l}\text { "But if you have a specific question for a specific category } \\
\text { of professionals, it is difficult to just call the hospital and } \\
\text { find a suitable person that can answer specific questions" }\end{array}$ & $\begin{array}{l}\text { Hard to get in contact with } \\
\text { the hospital and find someone } \\
\text { who can answer questions }\end{array}$ & $\begin{array}{l}\text { Ask the } \\
\text { expert }\end{array}$ & $\begin{array}{l}\text { Ask the } \\
\text { expert }\end{array}$ & \\
\hline
\end{tabular}

Figure I Overview of the structure of the content analysis. Example of condensation, through meanings units, condensed meaning units, subthemes, and themes.

appreciated that they could be in phone contact with their diabetes midwife, and the midwife would be able to access their information from the start page. At the same time, the women could contact other women in the same situation as themselves, as well as experts who could answer questions that the women were hesitant to ask face-to-face.

\section{Easily understood interface, but needs more blood glucose-focused orientation} Blood glucose more important than insulin

The women felt that insulin was only relevant in relation to blood glucose levels. Health care professionals and the diabetes midwife have an interest in precise insulin doses, but as a tool for diabetic women, the page layout slightly missed the focus of their concerns, because insulin was the dominant subject in the information presented on the page that they were required to fill in several times a day. Insulin doses are fairly consistent from day to day, and changes in dosage are generally observed over a longer period of time. As an alternative, the women in the interview recommended that a diagram for both blood glucose and insulin be included on the page so that they could choose to fill in the insulin doses when they wanted to see a pattern over time or when it was required by their diabetic midwife. One woman considered that, as a diabetic, blood glucose levels are already recorded in a booklet. A change in the diagram in the program was suggested so that it would be identical to

Table 2 Seven subthemes and two themes

\begin{tabular}{ll}
\hline Subtheme & Theme \\
\hline Blood glucose is more important & $\begin{array}{l}\text { Easily understood interface, } \\
\text { but in need of a more } \\
\text { than insulin }\end{array}$ \\
$\begin{array}{l}\text { The time aspect } \\
\text { olood glucose-focused } \\
\text { orientation }\end{array}$ \\
$\begin{array}{l}\text { Forum } \\
\text { Firect link to the diabetes midwife }\end{array}$ \\
$\begin{array}{l}\text { Ask the expert } \\
\text { back of contact information }\end{array}$ \\
\hline
\end{tabular}

that in their booklet. When the women tested the program, the $\mathrm{x}$ axis and the $\mathrm{y}$ axis were in reverse order compared with their booklet ("... I see my little booklet in front of me where I write all the time ...").

A function that would collect blood glucose levels directly from blood glucose monitors was considered desirable, and this was discussed with the women and the programmers. However, the programmers dismissed the suggestion because the market for monitors with different software and hardware is too broad and there is no standard solution.

\section{The time aspect}

Women in the focus group were reluctant to enter their blood glucose values directly into the program because they already tested their blood glucose levels frequently to maintain control. Although they had different methods of doing so, all of the women collected their blood glucose results from the monitors of their testing devices and transferred these to their booklet every evening, or might wait several days before transferring them. A calendar on the Website page showing results over a longer time period was considered desirable.

\section{Interface and technology}

Certain software functions were not fully developed on the day that testing of the Website took place. The women duly reported this shortcoming to the study investigators. There were also specific technical details that the programmers asked the participants about, and these were discussed and noted in the interview. For example, one of the women could not use the tab function when she was using the program. Another example was a green icon that was accessible on one page, but none of the women realized that the icon had a function and that there was information that could be accessed upon clicking on the icon. The women requested that they be able to make a comment on the page when they filled in their blood glucose levels instead of just checking 
a box indicating that they had eaten. All of the women were in agreement about this suggestion.

One of the women wanted to be able to choose an automatic logon function. ("It's like click and so rapid, because to keep up with these passwords and to look up half a book to find out which password you have and which pet you used as password is quite hard work.") Only one of the women had a smartphone and she was pleased about the possibility of accessing the functions of the program directly from her phone.

\section{Forum for interaction with peers and experts}

Forum

The most positive comments concerned the forum. The women considered the forum to be invaluable for coming into contact with other women in the same situation as themselves and who had the same life experience of diabetes that some health care providers lack. The forum was not solely focused on blood glucose levels, and would make a positive contribution to their network of information. ("... sure, those who work with diabetes and pregnancy know the facts of how diabetes works, but they can never understand the feelings that are involved, how you make it work in your everyday life, they can only provide tips about how others deal with it, it's easier to talk to someone who is actually in the exact same situation.")

An active forum in which they could participate would lead to increased use of the program and, as a consequence, the women would enter their blood glucose levels into the appropriate diagram when they logged in. The forum requires more structure than it presently has, and the threads seem to lack in continuity for specific subject categories. As it is constructed now, it is difficult to find a particular topic that users might potentially be interested in.

\section{Direct link to the diabetes midwife}

The results show that a direct link between the antenatal unit and a diabetes midwife was greatly appreciated. The women considered that this aspect of the program would save them a lot of time and also provide a more accurate and comprehensive overview in connection with their visit and consultation with the midwife at the hospital.

One woman reported that it would be "super" to have the opportunity to transfer blood glucose data in advance of their visit or directly to the antenatal unit. At the time of the study, the women were dictating their blood glucose results to the diabetic midwife by phone.

\section{Ask an expert}

One of the women reported feeling that it was a constant struggle when she had specific questions and needed to search for information or find the right person in the health care system to answer these questions. Having a channel in the structure of a forum for answering specific questions about pregnancy and diabetes was an aspect of key significance for the women.

\section{Lack of contact information}

The women were not content with a number of aspects of the design of the Webpage. They encountered difficulty accessing contact information from the research group and the midwife at the antenatal clinic. They expressed the hope that some link to questions commonly asked by their peers could be incorporated. They felt that there were aspects of the program that did not seem to be visually organized.

\section{Discussion Methods}

The qualitative content analysis method used to analyze the data and material in this study is considered to be suitable for analysis of interviews. The material was read and reread during the analytical process to preserve the concept as a whole, and it is probable that another research study would have come to the same conclusion based on the material that was gathered through this focus group interview. ${ }^{18}$ The strength of this study is that participants in the focus group were actually sitting in front of a computer monitor while actively testing a developing Website. The participants could react in real time to the program, while discussing and evaluating their feelings with each other and the creators of the Website. A conventional focus group would have consisted of an evaluation of the program after testing it, ${ }^{15}$ and some relevant details and information may have been lost in the evaluation.

Using a focus group interview technique posed a number of problems in this study. There were times when a number of people were talking at the same time, which made it difficult to transcribe the conversations from the tape recordings. Because the aim of this study was to get feedback from participants about the design of a new Website and its effectiveness, it would be impossible to compare the results against a study using a comparative design. Another difficulty was that some functions of the Website were not ready to be evaluated at the time of focus group testing and discussion. An example of this was the absence of an intended fifth page entitled "Facts" from the Website at the time of the study. 
The credibility of this study would have been enhanced by inclusion of a larger number of participants. There were originally five participants, and on the day of the study, two called in sick and were unable to participate. More time and money would have been required to make this study more comprehensive and broader. These constraints are seen as limiting factors.

\section{Results}

The main finding of this study was that the women tested their blood glucose frequently and were in control of their levels. As a result, the diagram on the front page of the Website now includes only blood glucose levels, and information on insulin is shown in graphical form. In other studies, women have expressed a need to have control of their blood glucose levels. ${ }^{6,7,10}$ The MODIAB-web prototype as tested in this focus group appeared to have substantial potential for helping women to maintain control of their blood glucose levels. It is critical for pregnant women with diabetes to have accurate blood glucose measurements because they risk possible harm to themselves ${ }^{4}$ and/or their babies if these are out of control. ${ }^{2,3}$ Blood glucose levels depend on a number of factors, including insulin dose, diet, stress levels, physical activity, and stage of pregnancy. All of these factors can be factored into the Website to give the women an accurate assessment of where they stand with regard to their levels. The input of the focus group into the prototype Website was valuable because it gave both the programmers and researchers some definite ideas on how to go about orienting the Website to the women's needs instead of what the traditional health care system used as standard operating procedure. One important change in the Website steered by the participants was the shift in focus from insulin dose to blood glucose levels as the priority. This input would eventually have an impact on the final layout of the MODIAB-web.

In addition to the ability to measure blood glucose levels accurately, the availability of this information to the diabetes midwife made the Website an asset to women with type 1 diabetes. Prior to the advent of the MODIAB-web, the relationship between women and the health care system was quite intensive because women were required to see the midwife once a week and have telephone contact up to every other day. ${ }^{11}$ With access to the Website, less personal contact is needed with the midwife at the antenatal unit, which helps both the women and the system to manage their diabetes and pregnancy care.

The focus group felt that the availability of the forum on the Website was the most important feature. The ability to be in contact with other women in the same situation was a significant asset. The results of a study by Berg and Sparud-Lundin ${ }^{8}$ showed that pregnant women with type 1 diabetes feel lonely in their pregnancy and that they need to share their experiences with other diabetics. Prior to the MODIAB-web prototype, no other Internet-based support was available for pregnant women with type 1 diabetes. Assessing the importance of online support was the objective of a study by van Uden-Kraan et al, ${ }^{14}$ who found that patients can benefit in general and even be empowered by online support groups. Specifically, pregnant women have been found to be dependent upon the Internet for pregnancy-related information, social networking, and support. ${ }^{12}$ In our study, the women in the focus group found it difficult to get answers to specific questions that they had regarding diabetes-related issues. The Website prototype also offered easier access to the health care system when it was necessary.

In addition to the forum, there is the availability of a couple of other sections that women can access. One of these is the "fact" tab where the women can access articles on issues for pregnant women with diabetes. Another section enables the women to put their own questions to a panel of experts.

\section{Conclusion}

The women in this focus group offered some very positive feedback with regard to the MODIAB-web prototype and concluded that it may function very well as a support tool for pregnant women with type 1 diabetes. They felt that there was significant room for improvement as well, and offered some much needed feedback on the system that the programmers and researchers could use to improve upon their prototype. Significant ideas from the women in the focus group were taken carefully into consideration during subsequent steps in the development of the MODIAB-web. Perhaps most significant was the fact that the women were more focused on their blood glucose levels, and other information was found to be less important. MODIAB-web is under clinical evaluation now, and a study of its impact on mothers with type 1 diabetes is in progress.

\section{Disclosure}

The authors report no conflicts of interest in this work.

\section{References}

1. Agardh C, Berne C, editors. Diabetes. 4th ed. Stockholm, Sweden: Liber; 2009.

2. ter Braak E, Evers I, Willem Erkelens D, Visser G. Maternal hypoglycemia during pregnancy in type 1 diabetes: maternal and fetal consequences. Diabetes Metab Res Rev. 2002;18:96-105. 
3. Inkster ME, Fahey TP, Donnan PT, Leese GP, Mires GJ, Murphy DJ. Poor glycated haemoglobin control and adverse pregnancy outcomes in type 1 and type 2 diabetes mellitus: systematic review of observational studies. BMC Pregnancy Childbirth. 2006;6:30.

4. Kapoor N, Sankaran S, Hyer S, Shehata H. Diabetes in pregnancy: a review of current evidence. Curr Opin Obstet Gynecol. 2007;19: 586-590.

5. Berg M, Lundgren I, Lindmark G. Childbirth experience in women at high risk: is it improved by use of a birth plan? J Perinatal Educ. 2003; $12: 1-15$.

6. Lavender T, Platt M, Tsekiri-O’Brien E, Hart A, Turner M, Cork M. Women's perception of being pregnant and having pregestational diabetes. Midwifery. 2010;26:589-595.

7. Berg M, Honkasalo ML. Pregnancy and diabetes - a hermeneutic phenomenological study of women's experiences. J Psychosom Obstet Gynaecol. 2000;21:39-48.

8. Berg M, Sparud-Lundin C. Experiences of professional support during pregnancy and childbirth - a qualitative study of women with type 1 diabetes. BMC Pregnancy Childbirth. 2009;9:27.

9. Langer N, Langer O. Pre-existing diabetics: relationship between glycemic control and emotional status in pregnancy. J Matern Fetal Med. 1998;7:257-263.

10. Berg M. Pregnancy and diabetes: how women handle the challenges. $J$ Perinat Educ. 2005;14:23-32.
11. Västra Götalandsregionen. Regionalt vårdprogram. Diabetes och graviditet. [Regional guidelines for diabetic and pregnancy.] Västra Götaland: Västra Götalandsregionen; 2008.

12. Lagan B, Sinclair M, Kernohan G. Internet use in pregnancy informs women's decision making: a web-based survey. Birth. 2010;37: 106-114.

13. Larsson M. A descriptive study of the use of the Internet by women seeking pregnancy-related information. Midwifery. 2009;25:14-20.

14. van Uden-Kraan CF, Drossaert CHC, Taal E, Seydel ER, van de Laar MAFJ. Participation in online patient support groups endorses patient's empowerment. Patent Educ Couns. 2009;74:61-69.

15. Wibeck V. Fokusgrupper. Om fokuserade gruppintervjuer som undersökningsmetod. [Focus Groups Interview. A book about the method of focus group interviews.] Lund, Sweden: Studentlitteratur; 2000.

16. Krippendorff K. Content Analysis: An Introduction to its Methodology. London, UK: Sage Publications Inc; 1980.

17. Coffey A, Atkinson P. Making Sense of Qualitative Data: Complementary Research Strategies. London, UK: Sage Publications Inc; 1996.

18. Graneheim UH, Lundman B. Qualitative content analysis in nursing research: concepts, procedures and measures to achieve trustworthiness. Nurse Educ Today. 2004;24:105-112.

19. Baxter LA. Content analysis. In: Montgomery BM, Duck S, editors. Studying Interpersonal Interaction. New York, NY: Guilford Press; 1991.

\section{Publish your work in this journal}

Psychology Research and Behavior Management is an international, peerreviewed, open access journal focusing on the science of psychology and its application in behavior management to develop improved outcomes in the clinical, educational, sports and business arenas. Specific topics covered include: Neuroscience, memory \& decision making; Behavior

\section{Dovepress}

modification \& management; Clinical applications; Business \& sports performance management; Social and developmental studies; Animal studies. The manuscript management system is completely online and includes a quick and fair peer-review system. Visit http://www.dovepress com/testimonials.php to read real quotes from published authors. 